Revista Thema

V.20 Especial 2021

p.181-200
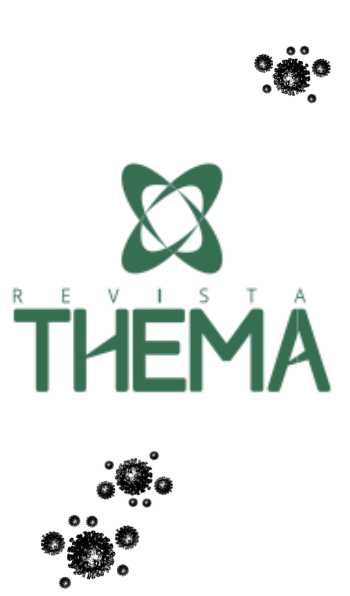

DOI: http://dx.doi.org/10.15536/thema.V20.Especial.2021.181-200.1866

ISSN: 2177-2894 (online)

\title{
O uso de tecnologias digitais e mídias sociais por profissionais da saúde no período da pandemia da COVID-19
}

\author{
The use of digital technologies and social media by health \\ professionals in the COVID-19 pandemic period \\ Maria Bethânia Tomaschewski Bueno ${ }^{1}$, Mateus Moreira Bueno², \\ Maria Isabel Giusti Moreira ${ }^{3}$
}

\section{RESUMO}

No final do ano de 2019 e ainda em curso no ano de 2020, um vírus altamente contagioso desestruturou os sistemas de saúde, educacionais, econômicos e de produção e tornou-se um desafio sanitário em escala mundial. Com o distanciamento social como medida de enfrentamento, emergiu a problematização desta pesquisa: 'Como os profissionais da saúde percebem as Tecnologias Digitais e as Mídias Sociais no período da Pandemia da COVID-19 no Brasil?'. A metodologia utilizada foi qualiquantitativa, o instrumento para a coleta de dados foi o Google Forms. Os sujeitos pesquisados foram profissionais da área da saúde, pertencentes as regiões Sul e Sudeste do Brasil. Foram convidados a responder 56 profissionais, entretanto apenas 15 sujeitos responderam à pesquisa. Os resultados demonstraram o uso preponderante do aplicativo WhatsApp e a comunicação virtual possibilitou a manutenção do contato com pacientes e/ou alunos. No entanto há dois olhares perante as Mídias Sociais e as Tecnologias Digitais por esses profissionais, um progressista em relação ao uso dessas ferramentas a partir da pandemia e o outro, de que serão afastadas do cotidiano desses profissionais.

Palavras-chave: Ensino em Saúde; tecnologias digitais de informação e comunicação; telessaúde; coronavírus.

\section{ABSTRACT}

At the end of 2019 and still underway in the year 2020, a highly contagious virus has disrupted health, educational, economic and production systems and has become a worldwide health challenge. With social distance as a coping measure, the questioning of this research emerged: 'How do health professionals perceive Digital Technologies and Social Media in the period of the COVID-19 Pandemic in Brazil?'. The methodology used was qualitative and quantitative, the

\footnotetext{
${ }^{1}$ Mestranda em Ciências e Tecnologias na Educação, Instituto Federal de Educação, Ciência e Tecnologia Sul-rio-grandense, Campus Pelotas-Visconde da Graça/RS - Brasil. E-mail: bethaniatomaschewsky@ gmail.com

${ }^{2}$ Graduado em Engenharia de Produção, pela Universidade Federal de Pelotas - UFPel, Pelotas/RS - Brasil. E-mail: bueno.mateus@gmail.com

${ }^{3}$ Instituto Federal de Educação, Ciência e Tecnologia Sul-rio-grandense, Campus Pelotas-Visconde da Graça/RS - Brasil. E-mail: isabelmoreira@gmail.com
} 
instrument for data collection was Google Forms. The researched subjects were health professionals, belonging to the South and Southeast regions of Brazil. 56 professionals were invited to respond, however only 15 subjects responded to the survey. The results demonstrated the predominant use of the WhatsApp application and virtual communication made it possible to maintain contact with patients and / or students. However, there are two perspectives on Social Media and Digital Technologies by these professionals, one progressive in relation to the use of these tools from the pandemic and the other, which will be removed from the daily lives of these professionals.

Keywords: Health education; digital information and communication technologies; telehealth; coronavirus.

\section{INTRODUÇÃO}

No final do ano de 2019 e ainda em curso no ano de 2020, um vírus altamente contagioso desestruturou os sistemas de saúde, educacionais, econômicos e de produção e tornou-se um desafio sanitário em escala mundial. O vírus corresponde a família de Coronavírus, o Severe Acute Respiratory Syndrome Coronavirus 2 (SARSCov-2), em que causa uma debilidade respiratória severa e a doença em decorrência desse vírus foi denominada de COVID-19. (OMS, 2020a; OMS, 2020b; OPAS, 2020; BRASIL, 2020).

O SARS-Cov-2 foi identificado primeiramente em dezembro de 2019 em Wuhan, na província de Hubei, China, em consequência a um número expressivo de casos de pneumonia. Foi em março de 2020 que a Organização Mundial de Saúde (OMS) o designou como pandemia, devido a sua veloz contaminação entre seres humanos e na proporção da sua disseminação em diversos países. (OMS, 2020a; OMS, 2020b; BRASIL, 2020; MOOCK; MELLO, 2020; GUIMARÃES, 2020).

A COVID-19 trata-se de uma doença infecciosa humana e as evidências disponibilizadas pelas entidades cientificas até o presente momento são de que os sintomas leves se constituem em febre, cansaço, tosse seca, coriza e a dor de garganta, esses sintomas vão gradualmente piorando, o que proporciona em falta de ar severa e pneumonia. Com isso, esse vírus acabou sobrecarregando os serviços de saúde, principalmente as Unidades de Terapia Intensiva (UTIs), originando um colapso da rede de saúde em algumas localidades. (OPAS, 2020; GUIMARÃES, 2020; BRASIL, 2020).

Como ainda não há antivirais nem vacina para esse caso, os órgãos responsáveis pelo enfretamento da COVID-19 definiram uma série de ações para o combate, sendo essas, a higiene constante de mãos, higienização e desinfecção de superfícies, utensílios e vestuários, etiqueta respiratória, distanciamento social e em alguns casos o isolamento social. Além disso, a utilização de máscaras cirúrgicas para a proteção respiratória, e dependendo do meio a utilização de luvas e aventais descartáveis, para o uso fora das residências. (OMS, 2020a; OMS, 2020b; BRASIL, 2020; BARRETO et al., 2020). 
A pandemia por COVID-19, ainda em curso, ocasionou em uma desestruturação de nível global nas esferas econômica e social, assim como nos contextos das estruturas educacionais e de trabalho. A crise de dimensão global exigiu a todos os envolvidos, isto é, governos, empresas, trabalhadores formais e informais, alunos, instituições de ensino de diversos níveis, entre outros, a ressignificação frente a inserção das Tecnologias Digitais no processo de ensino e de aprendizagem. (AVELINO; MENDES, 2020; BARRETO et al., 2020).

Assim como, a reflexão perante as inovações tecnológicas de modo amplo e os modelos de organização no trabalho também foram e estão sendo discutidas em diversos setores de produção e áreas profissionais. Por exemplo, em determinados setores ou profissões era imaginável o home office, e essa questão tornou-se realidade a partir do estabelecimento das estratégias de enfretamento da pandemia da COVID-19, como o isolamento social.

As medidas de enfrentamento a pandemia da COVID-19 condicionaram aos indivíduos a se adaptarem a atual realidade, reestruturando suas atividades profissionais, educacionais, de lazer, consumo e perspectivas a conectividade. Por intermédio dos meios tecnológicos digitais, essa realidade possibilitou aos indivíduos que minimizassem a ruptura nos atendimentos a pacientes e clientes, as atividades acadêmicas, reuniões e desenvolvimento de produtos, por exemplo. (MENDONÇA et al., 2020; PALÁCIO; TAKENAMI, 2020; CHURKIN, 2020; CECCON; SCHNEIDER, 2020).

Nesse sentido, os profissionais da área da saúde obtiveram a possibilidade de amparar-se, quando possível, nessas Tecnologias Digitais ao que tange a educação e o ensino em saúde, a manutenção de suas atividades acadêmicas, Telemonitoramento e Telessaúde. Todavia, nem todos os serviços da área da saúde são possíveis remotamente, há aqueles profissionais que compõe a rede de atuação no cuidado a saúde da população em que as intervenções presenciais são cruciais para a conservação da vida. (MENDONÇA et al., 2020; PALÁCIO; TAKENAMI, 2020; CECCON; SCHNEIDER, 2020).

No entanto, há aqueles que se encontram e ainda permanecem em reclusão domiciliar e possuem a alternativa de manter suas atividades, mesmo que reduzidas. Visando compreender as percepções de profissionais da área da saúde, atuantes em suas especialidades assim como formadores de outros profissionais da área, perante as Tecnologias Digitais e as Mídias Sociais em suas atividades profissionais nesse período da pandemia, a problematização desta pesquisa dá-se da seguinte maneira: Como os profissionais da saúde percebem as Tecnologias Digitais e as Mídias Sociais no período da Pandemia da COVID-19 no Brasil?

Justifica-se esse estudo, na intenção de, em um primeiro momento verificar quais as medidas tomadas por esses profissionais nesse período frente a atuação e manutenção de suas atividades, seja com pacientes e/ou alunos. Posteriormente, reverberar reflexões na área da saúde frente a flexibilidade e diversidade do uso dessas inovações tecnológicas na área. 


\section{METODOLOGIA}

A metodologia utilizada nesta pesquisa foi qualiquantitativa, no qual é o tipo de abordagem que associa dados qualitativos e dados quantitativos. (BRASILEIRO, 2013, p.49). Como preconiza esse procedimento metodológico, foi utilizado como instrumento para a coleta de dados o questionário semiestruturado, aplicado por meio do Google Forms ou para a tradução livre o Formulário do Google.

Compreende-se que apesar da nomeação de formulário, esse instrumento se caracteriza como um questionário semiestruturado, seguindo a visão de Brasileiro (2013). Visto que pela autora, "formulário é o instrumento estruturado em uma série de questões, cujas respostas devem ser registradas por um entrevistador numa situação face a face com o informante." (BRASILEIRO, 2013, p.50).

Ainda segundo a autora, o questionário semiestruturado mescla questões abertas e fechadas, segue uma estrutura lógica da questão mais simples a mais complexa e deve ser compreensível aos destinatários. (BRASLEIRO, 2013, p.51). Assim, os autores desta pesquisa optaram por um questionário objetivo e que simultaneamente possibilitasse aos sujeitos discursarem de maneira à vontade sobre a temática, de modo remoto devido ao isolamento social.

As questões abertas foram tratadas pela técnica do Discurso do Sujeito Coletivo (DSC), segundo Lefèvre e Lefèvre (2005). O DSC é uma técnica de resgate da opinião coletiva, em que a partir dos depoimentos individuais de um determinado grupo sobre determinado tema é realizado um processo complexo em que é efetuado determinadas operações e assim, transformando todo o material coletado em um ou mais discursos que representam esse coletivo. (LEFÈVRE et al., 2010; LEFÈVRE; LEFÈVRE, 2005).

A pesquisa típica que usa o DSC é uma pesquisa de opinião sobre dado tema, dividida em três, quatro ou cinco questões abertas a serem respondidas por uma dada amostra de população; cada uma destas questões gera um número variado de diferentes posicionamentos, ou seja, de distintos DSCs.

Esses DSCs são distintos tanto do ponto de vista qualitativo, na medida em que veiculam opiniões e posicionamentos distintos, como do ponto de vista quantitativo, uma vez que cada um deles é o resultado da contribuição de um determinado número de entrevistas ou depoimentos de indivíduos que, ademais, são portadores de determinados atributos demográficos. (LEFĖVRE; LEFÈVRE, 2005, p.23).

As questões devem ser abertas e individuais nessa técnica, pois possibilita a esses sujeitos pesquisados a expressão verdadeira e espontânea sobre o tema proposto. Na Figura 1 é evidenciada uma breve explanação do processo de formação do DSC, em que esses depoimentos expressados pelos sujeitos são organizados e tabelados, de modo que não exponham sua identidade. Logo, passam por quatro operações denominadas de: Expressões-Chave (E-Ch), Ideias Centrais (ICS), Ancoragens (ACs) e o Discurso do Sujeito Coletivo (DSC). 
Após o processo o discurso coletivo final ou DSC é escrito na primeira pessoa do singular, como um 'Eu ampliado' ou um ser empírico coletivo. (LEFĖVRE et al., 2010; LEFĖVRE; LEFÈVRE, 2005; LEFÈVRE; LEFÈVRE, 2014). Isto é, a partir de vários fragmentos de discursos sobre determinado tema, de diversos indivíduos de um determinado contexto, formam um discurso que representará o pensamento desses sujeitos sobre esse determinado assunto, mas como um sujeito.

Figura 1 - Breve explanação do processo de formação do DSC.

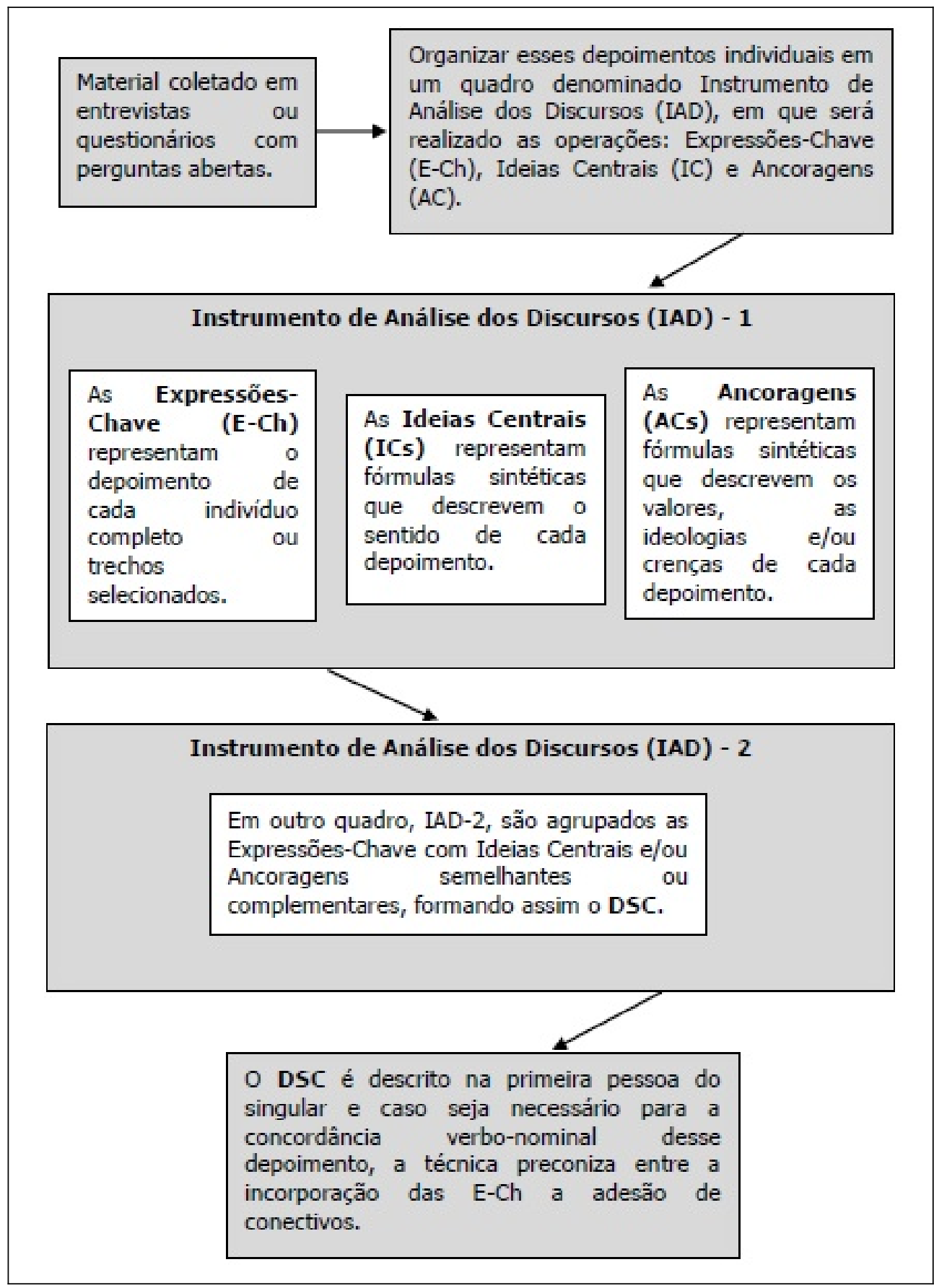

Fonte: Elaborados pelos autores com base em Lefèvre e Lefèvre (2005). 
O questionário desta pesquisa foi divido em três seções, a primeira seção trazia como título 'Pesquisa sobre a utilização de Tecnologias Digitais e Mídias Sociais pelos Profissionais da Área da Saúde', seguido da explicação do que se tratava a pesquisa e seus autores responsáveis. A segunda seção estava intitulada de 'Informações sobre os Sujeitos Pesquisados', em que constava algumas indagações, de modo a descrever sem identificar os sujeitos delineados.

A terceira e última seção era composta por seis questionamentos. A primeira questão era aberta e foi descrita da seguinte maneira: 'Como as Mídias Sociais auxiliaram e ainda auxiliam no contato com os seus pacientes/alunos nesse período da Pandemia da COVID-19?'.

A segunda questão aberta foi descrita como: 'Já havia utilizado as Tecnologias Digitais para supervisão, manutenção ou educação em saúde antes da Pandemia da COVID19? Caso seja sim, de que maneira você utilizou? '. A terceira questão é demonstrada na Figura 2, em que foi perguntado 'Qual o canal na Internet e/ou Mídias Sociais você utilizou e está utilizando para o contato com seus pacientes/alunos, nesse período da Pandemia da COVID-19?', e havia opções para os sujeitos assinalarem de modo acumulativo, assim como a opção 'Outros' onde esse poderia acrescentar sua observação faltante.

Figura 2 - Imagem da questão referente ao canal de Internet e/ou Mídia Social utilizada pelo profissional da saúde.

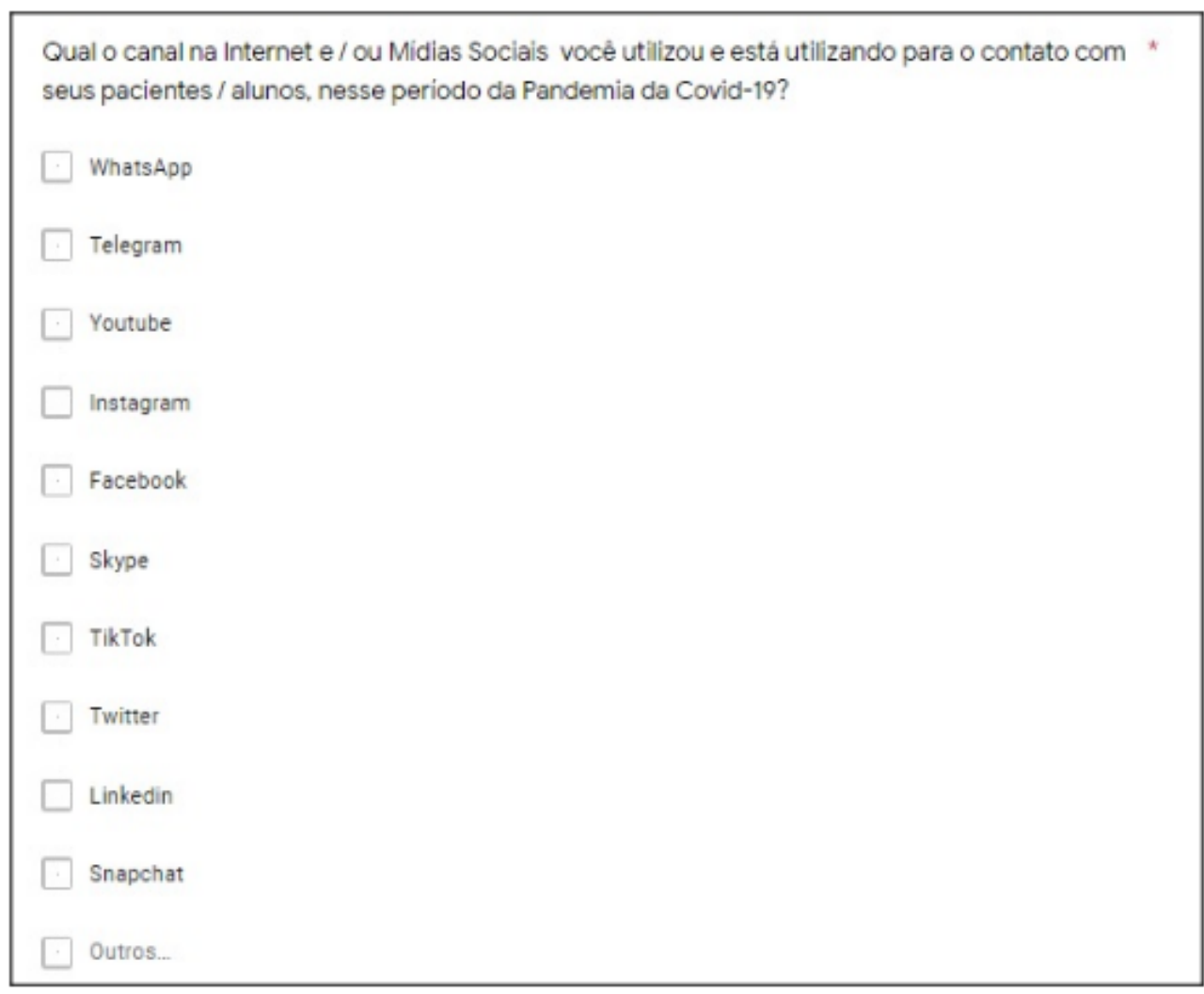

Fonte: Pesquisa (2020). 
Na Figura 3 é demonstrado o quarto questionamento da seção, com a interrogativa 'Qual Tecnologia Digital você utilizou e está utilizando com seus pacientes/alunos nesse período da Pandemia da COVID-19? '. Da mesma forma que a questão anterior, havia opções para assinalar de modo acumulativo e a opção 'Outros' para acrescentar observações.

Figura 3 - Imagem da questão sobre a utilização da Tecnologia Digital utilizada no período da COVID-19.

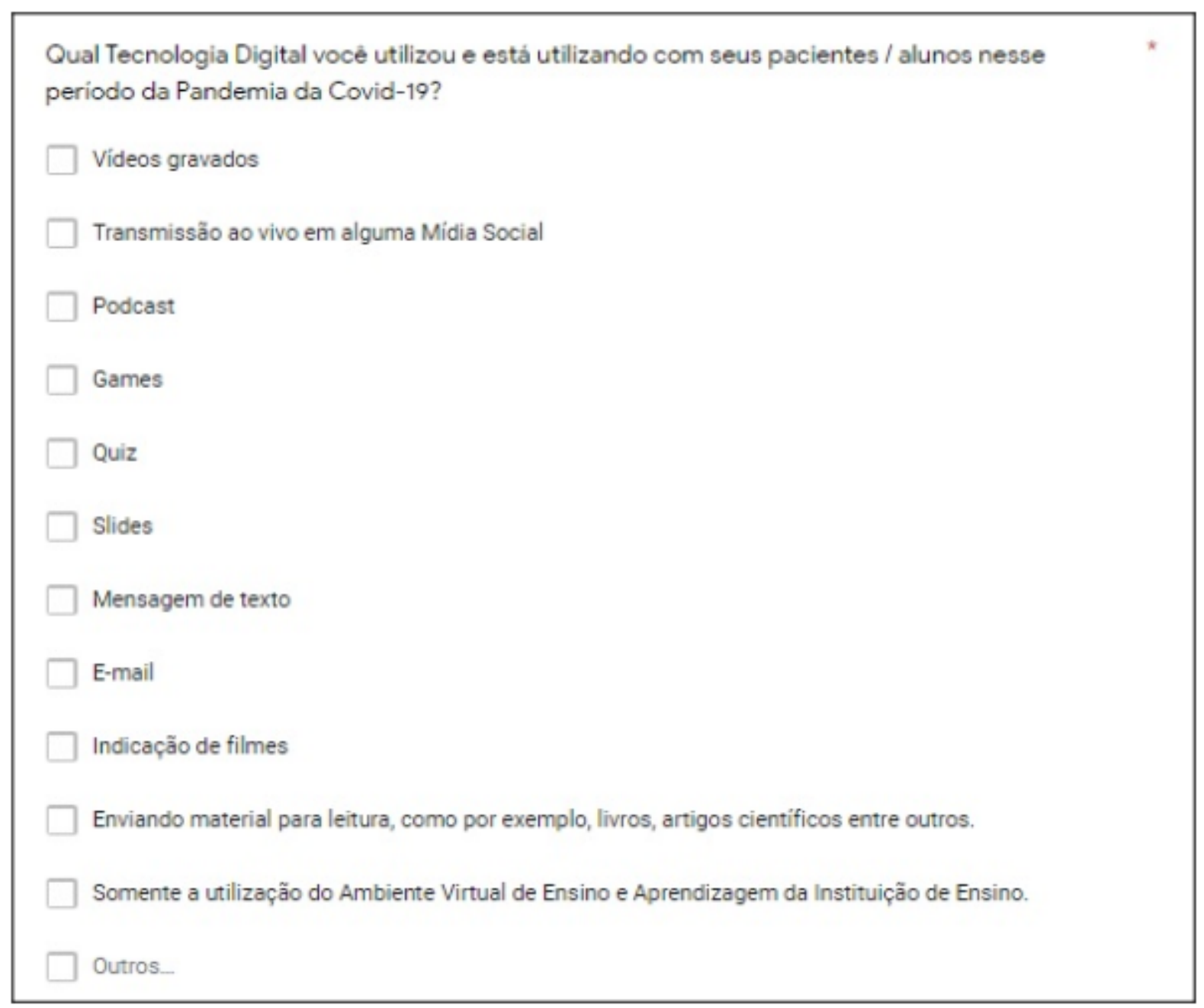

Fonte: Pesquisa (2020).

As últimas duas questões foram abertas e descritas em 'Como você percebe a utilização das Tecnologias Digitais no exercício dos profissionais da área da saúde? ', e em 'Como você percebe o período após a Pandemia de COVID-19 em suas relações de trabalho com as Tecnologias Digitais?'.

Os sujeitos pesquisados foram selecionados aleatoriamente por meio de Mídias Sociais e a convite aos endereços de e-mails, com o delineamento de serem professores e/ou profissionais da área da saúde, pertencentes as regiões Sul e Sudeste do Brasil. Esta pesquisa foi realizada no período entre os meses de abril a junho de 2020 . Nos meses 
de abril a maio, foram aplicados os questionários aos sujeitos e a escrita introdutória desta, no mês de junho foram organizados os resultados e assim, a finalização da escrita da pesquisa.

\section{RESULTADOS}

Foram convidados a responder o questionário semiestruturado 56 profissionais da área da saúde, sendo esses atuantes em suas especialidades e/ou na docência, via e-mails e Mídias Sociais, como anteriormente descrito. Entretanto, apenas 15 sujeitos responderam à pesquisa no tempo determinado.

As questões abertas foram tratadas com a técnica do DSC e estão dispostas no final dessa seção. São elas: 'Como as Mídias Sociais auxiliaram e ainda auxiliam no contato com os seus pacientes/alunos nesse período da Pandemia da COVID-19? ', 'Já havia utilizado as Tecnologias Digitais para supervisão, manutenção ou educação em saúde antes da Pandemia da COVID-19? Caso seja sim, de que maneira você utilizou? ', 'Como você percebe a utilização das Tecnologias Digitais no exercício dos profissionais da área da saúde? ' e 'Como você percebe o período após a Pandemia de COVID-19 em suas relações de trabalho com as Tecnologias Digitais? '.

Dos 15 sujeitos que responderam o questionário, 53,333333\% (8) eram do sexo feminino como é evidenciado na Figura 4.

Figura 4 - Imagem da divisão por sexo dos participantes da pesquisa.

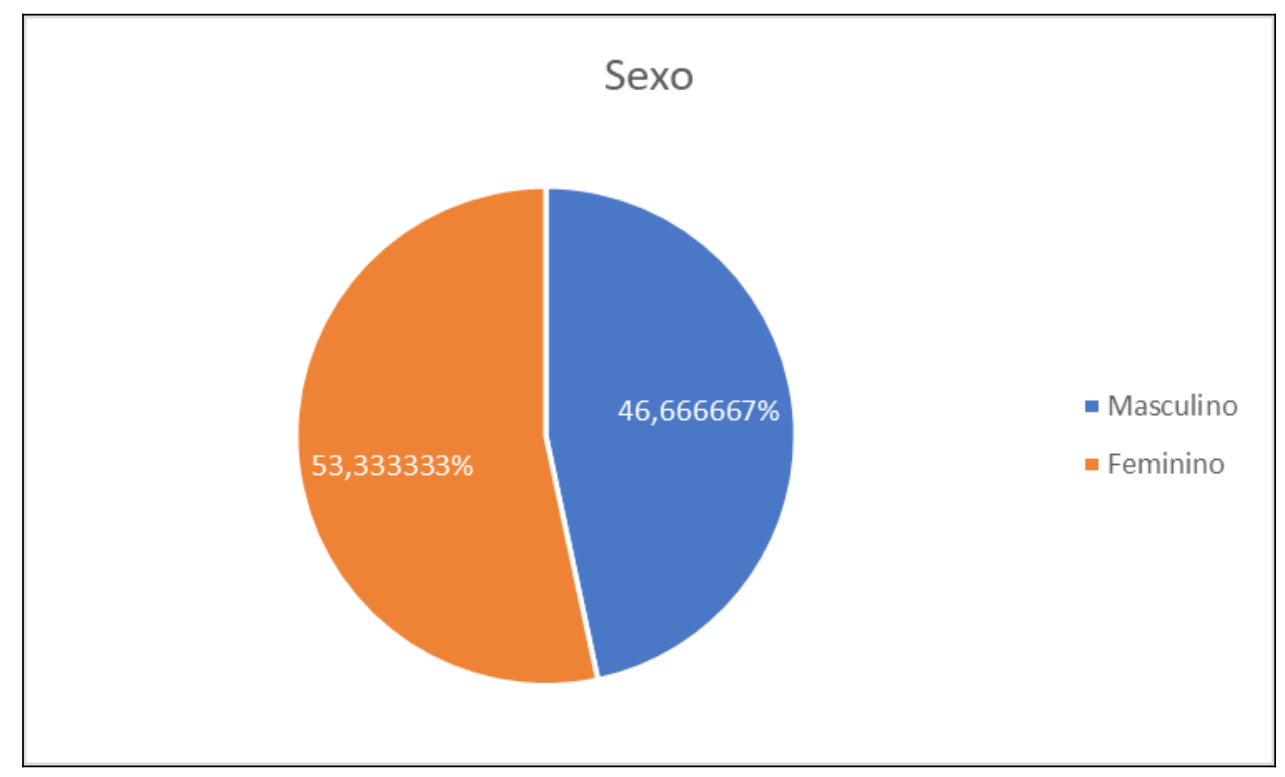

Fonte: Pesquisa (2020).

As idades dos participantes variaram entre 23 a 56 anos, as profissões desses participantes foram descritas em: 66,666667\% (10) eram Fisioterapeutas, 6,666667\% (1) Educador Físico, 6,666667\% (1) Psicólogo, 6,666667\% (1) Médica Veterinária 6,666667\% (1) Médico e 6,666667\% (1) Enfermeiro. 
As especialidades desses sujeitos foram descritas por eles como: Docente, Quiropraxia, Fisioterapia Esportiva, Professora de Pilates, Neurofuncional, Psicologia Clínica e Psicologia Organizacional, Dermatofuncional, Professor de Clínica Médica, Traumatologia e Ortopedia. Os resultados sobre as titulações dos sujeitos pesquisados foram de 20\% (3) com Pós-doutorado, 6,666667\% (1) Doutorando, 20\% (3) com Mestrado completo, 6,666667\% (1) Mestrando, 33,333333\% (5) com Especialização completa, 6,666667\% (1) com Especialização em andamento e 6,666667\% (1) com a Graduação.

Na Figura 5 é evidenciado a questão ‘Qual o canal na Internet e/ou Mídias Sociais você utilizou e está utilizando para o contato com seus pacientes/alunos, nesse período da Pandemia da COVID-19? ', em que resultou em o uso do 'WhatsApp' como a ferramenta mais utilizada pelos profissionais da área da saúde pesquisados, com 93,333333\% (14) de relato de utilização. Posteriormente, o 'Instagram' com $53,333333 \%$ (8) dos relatos, o 'Youtube', 'Facebook' e o 'Skype' com 40\% (6) cada, o 'Zoom' com 13,333333\% (2), o 'Telegram' também conta com 13,333333\% (2), o 'Twitter', o 'Linkedin', o 'Whereby' e o 'Hangouts' cada um com 6,666667\% (1) dos relatos.

Ainda sobre os resultados evidenciados na Figura 5, as opções 'TikTok' e 'Snapchat' não foram selecionadas, logo $0 \%$. Ressalta-se que essa questão obtinha como possibilidade a escolha das opções de maneira acumulativa, isto é, possibilitava aos sujeitos marcar mais de uma opção.

Figura 5 - Demonstração dos canais de Internet e/ou Mídias Sociais utilizadas pelos sujeitos pesquisados.

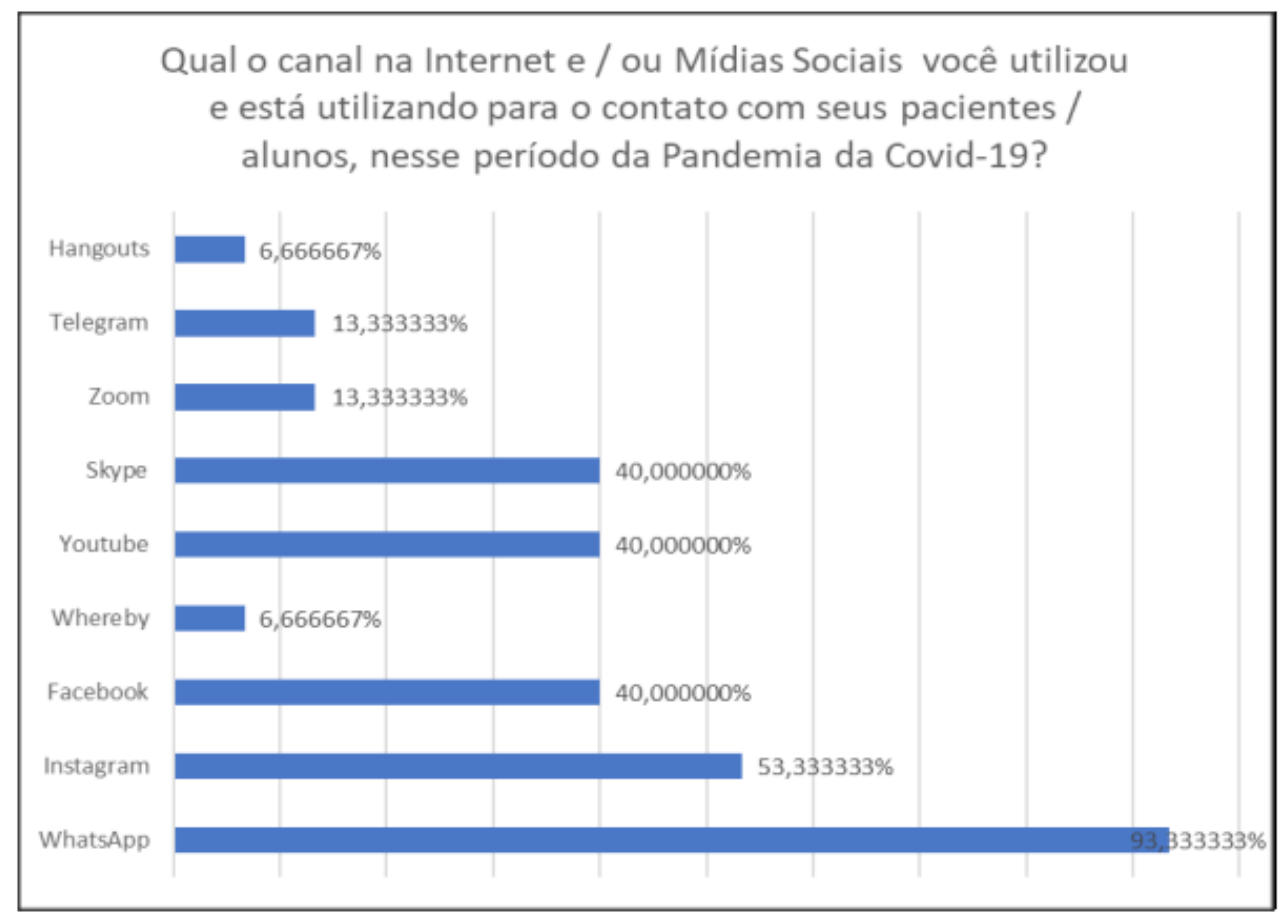

Fonte: Pesquisa (2020). 
Na questão 'Qual Tecnologia Digital você utilizou e está utilizando com seus pacientes/alunos nesse período da Pandemia da COVID-19? ', as principais tecnologias utilizadas pelos sujeitos desta pesquisa são evidenciadas na Figura 6. Conforme a figura, é possível analisar que os profissionais da área da saúde pesquisados neste estudo assinalaram a opção ‘Enviando material para leitura, como por exemplo, livros, artigos científicos entre outros. ' com 73,333333\% (11) dos relatos, posteriormente a 'Transmissão ao vivo em alguma Mídia Social' com 66,666667\% (10) e 'Vídeos gravados' com 53,333333\% (8) dos relatos.

Ainda sobre essa questão e com pouca inclusão do uso por esses profissionais, são descritos a 'Mensagem de texto' e o 'E-mail' com 46,666667\% (7) cada, o uso de 'Slides' com 26,666667\% (4), 'Indicação de filmes' e 'Somente a utilização do Ambiente Virtual de Ensino e Aprendizagem da Instituição de Ensino' com 20\% (3) cada, o 'Podcast', o 'Quiz' e o 'Áudio' cada um com 6,666667\% (1). Além disso, a opção 'Games' não foi selecionada, logo $0 \%$ e essa questão também obtinha a possibilidade de marcar mais de uma opção.

Figura 6 - As principais Tecnologias Digitais utilizadas pelos sujeitos pesquisados.

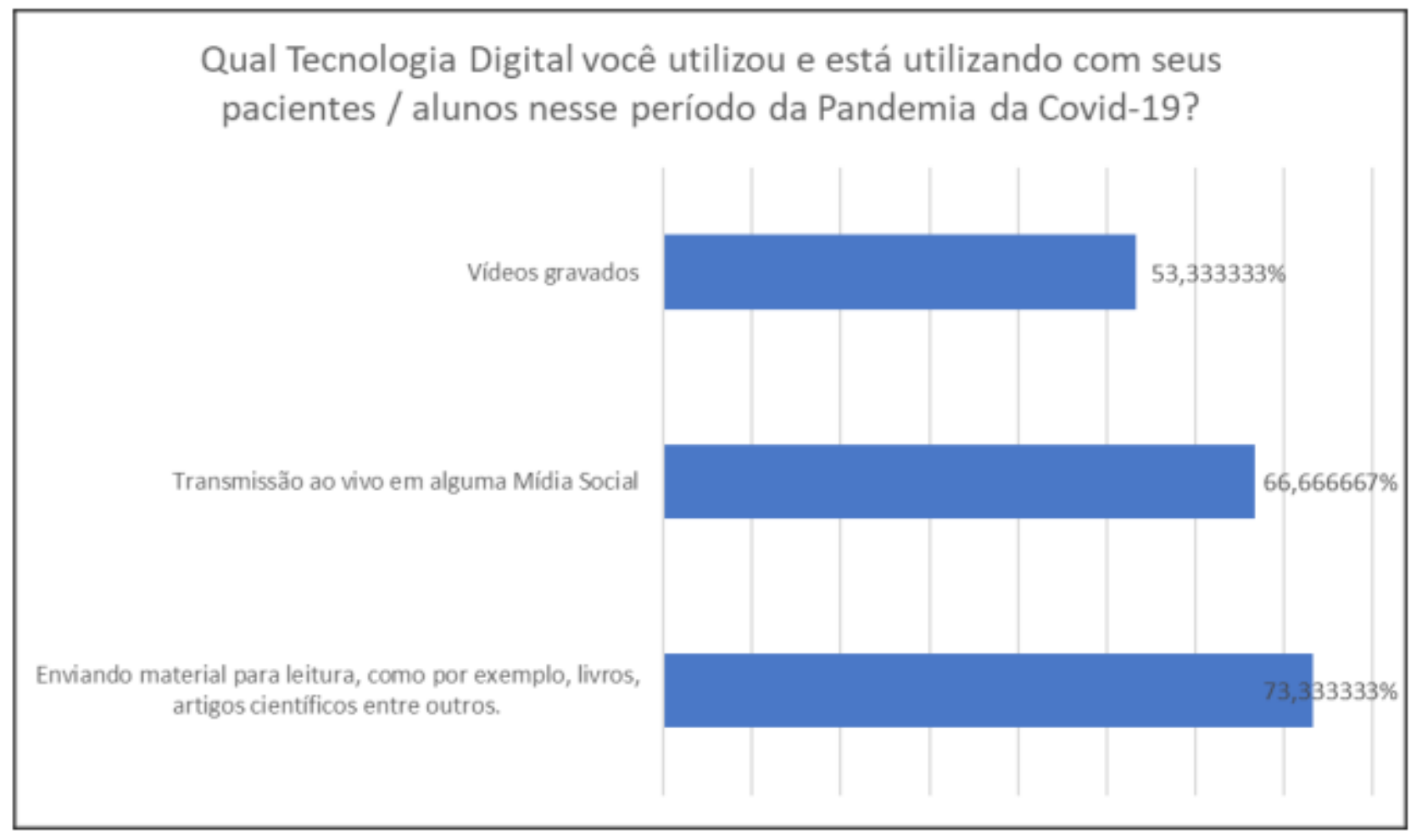

Fonte: Pesquisa (2020).

As quatro questões abertas foram tratadas com a técnica do Discurso do Sujeito Coletivo (DSC), como anteriormente mencionado e originaram seis Discursos do Sujeito Coletivo. A primeira questão, 'Como as Mídias Sociais auxiliaram e ainda auxiliam no contato com os seus pacientes/alunos nesse período da Pandemia da 
COVID-19? ', originou dois DSC's, o primeiro DSC é demonstrado no Quadro 1 com o título 'As Mídias Sociais não auxiliam no contato com os pacientes e os alunos'.

Quadro 1 - DSC 1 - As Mídias Sociais não auxiliam no contato com os pacientes e os alunos.

Como as Mídias Sociais auxiliaram e ainda auxiliam no contato com os seus pacientes/alunos nesse período da Pandemia da Covid-19?

Não auxiliam, pelo contrário, no meu caso ainda provoca uma dúvida se a mídia é tão eficaz quanto ao vivo e em cores.

Fonte: Pesquisa (2020).

O Quadro 1 apresenta o primeiro discurso coletivo em que evidencia o não auxilio das Mídias Sociais no contato com os pacientes e/ou alunos nesse período da Pandemia da COVID-19. Ainda segundo esse sujeito coletivo há dúvidas em relação a utilização das mídias em comparação a presença física do profissional e aluno/paciente.

O segundo DSC resultante da primeira questão, demonstrado no Quadro 2, tem como título 'As Mídias Sociais ajudam com informações em tempo real'.

Quadro 2 - DSC 2 - As Mídias Sociais ajudam com informações em tempo real.

Como as Mídias Sociais auxiliaram e ainda auxiliam no contato com os seus pacientes/alunos nesse período da Pandemia da Covid-19?

Bem, uso todas elas diariamente com a finalidade de home office. Ajudam a dar atendimento online através da possibilidade de reuniões com orientandos e entre docentes. Assim como informações em tempo real, com todos em casa e as universidades enviando conteúdo freneticamente sem critério, os alunos procuram algo mais organizado como informações, distribuição de tarefas, comunicação, desse modo todos os contatos e atividades são enviadas aos alunos por meio eletrônico, além de possibilitar contato com alunos de pós-graduação por reuniões virtuais. Além disso, utilizamos nossas mídias para divulgar a informação sobre atendimentos de pacientes agudos que necessitarem do serviço de fisioterapia Quiropráxica, está sendo útil para orientar os responsáveis dos pacientes a atividades que possam ser realizadas em casa, por eles, para ajudar na manutenção da terapia realizada antes da pandemia. Em suma, para continuarmos com o contato/vínculo, a fim de mantermos conectados podendo assim orientar os nossos pacientes.

Fonte: Pesquisa (2020).

Diferentemente do Quadro 1, o Quadro 2 evidencia um depoimento em que o uso das Mídias Sociais é realizado diariamente e auxiliam na possibilidade de reuniões virtuais com alunos, nos atendimentos e orientações de atividades para os pacientes, por exemplo. Nesse DSC, esse sujeito coletivo expressa que em meio a Pandemia da 
COVID-19 as Mídias Sociais possibilitaram o home office, mesmo aos profissionais da área da saúde.

A segunda questão, 'Já havia utilizado as Tecnologias Digitais para supervisão, manutenção ou educação em saúde antes da Pandemia da COVID-19? Caso seja sim, de que maneira você utilizou?', originou um DSC, demonstrado no Quadro 3.

\section{Quadro 3 - DSC 3 - Utilizando as Tecnologias Digitais para compartilhamentos de conteúdo.}

Já havia utilizado as Tecnologias Digitais para supervisão, manutenção ou educação em saúde antes da Pandemia da Covid-19? Caso seja sim, de que maneira você utilizou?

Sim, mas pouca, basicamente com reuniões online e compartilhamento de vídeos. Na área educacional sim, dando continuidade a explicação de conteúdo e atividades extras, por exemplo, possuo 3 plataformas digitais e faço tutorias online com alunos há mais de 5 anos, com envio de materiais online (vídeos, simulados, podcasts, apostilas, etc.) e cursos ead, do mesmo modo - reunião com orientandos que não residem na mesma cidade. Já no âmbito de atendimento e orientação em relação a exercícios relacionados a terapia é a primeira vez, não apenas utilizando o app WhatsApp, Facebook, Instagram, Twitter e YouTube, mas fazendo publicações sobre prevenção e vídeos explicativos, assim utilizamos nossas mídias para educação em dor e também para divulgação de condutas para o manejo de distúrbios da coluna vertebral, embora muito difícil as adaptações as plataformas não estão prontas para toda essa sobrecarga.

Fonte: Pesquisa (2020)

O terceiro DSC oriundo da segunda questão com o título de 'Utilizando as Tecnologias Digitais para compartilhamentos de conteúdo', evidencia a progressão do uso das Tecnologias Digitais por esse sujeito coletivo, na área educacional já existia um domínio como foi expressado por esse, no entanto para o âmbito de atendimento relacionado a terapia foi inicial. Outro fator abordado foi a dificuldade de adaptação, segundo o depoimento, as plataformas não estão preparadas para a sobrecarga.

A terceira questão, 'Como você percebe a utilização das Tecnologias Digitais no exercício dos profissionais da área da saúde? ', originou um DSC com o título de 'Ferramenta eficaz, mas subutilizada', demonstrado no Quadro 4.

No Quadro 4 é demonstrado o quarto DSC com o título 'Ferramenta eficaz, mas subutilizada', em que descreve as Tecnologias Digitais como uma ferramenta eficaz e aliada para a permanência no contato com os pacientes, principalmente no período da Pandemia da COVID-19, devido a reclusão domiciliar. Contudo, esse depoimento relata a necessidade de preparação e a preocupação por não gerar nessa ferramenta um recurso de atendimento, pois segundo o mesmo, é uma ferramenta limitada principalmente no tratamento fisioterapêutico. 
Quadro 4 - DSC 4 - Ferramenta eficaz, mas subutilizada.

\begin{abstract}
Como você percebe a utilização das Tecnologias Digitais no exercício dos profissionais da área da saúde?

Percebo uma ferramenta muito eficaz, sempre pensando no bem estar do paciente, com efeito importante para continuarmos orientando, ajudando e não deixando nossos pacientes sem amparo, pois muitos deles nesse momento ficam sem vontade de continuar com suas atividades diárias devido elas terem que serem feitas em casa, com isso o contato e a educação do paciente para enfrentar seus males é facilitado pelas tecnologias digitais. Nesse sentido está ajudando muito aos profissionais que dependem a maioria das vezes dos pacientes, a manterem o contato, embora vejo ainda subutilizada e com muitos profissionais tendo preconceito com criadores de conteúdo para profissionais de saúde, apesar desses mesmos profissionais usarem redes sociais para divulgação de seus conteúdos. Por outro lado, há instituições que estão se organizando para isso, mas penso que há muitas dificuldades devido a nem todos os estudantes possuírem acesso até o momento. Acredito sim, enquanto aliado, como algo novo e pouco explorado, inegavelmente em crescimento, mas ainda precisa de maior preparação, talvez não sei, com dificuldade, porque estamos vivendo um momento atípico onde a tecnologia está sendo ao nosso favor, porém não deve perdurar, pelo menos na minha área de atuação, por isso preocupante por vezes, pois temos que ter o cuidado de não gerar com que essa ferramenta vire um recurso de atendimento. Em resumo, uma ferramenta importante, totalmente favorável e necessária, mas ainda bastante limitada, principalmente no tratamento do escopo fisioterápico.
\end{abstract}

Fonte: Pesquisa (2020).

A quarta questão, 'Como você percebe o período após a Pandemia de COVID-19 em suas relações de trabalho com as Tecnologias Digitais? ', originou dois DSC's. No Quadro 5 é demonstrado o quinto DSC com o título de 'Período de ótimos conhecimentos digitais' e no Quadro 6 é evidenciado o sexto DSC com o título 'As atividades seguirão no modo tradicional'.

O Quadro 5 apresenta o quinto DSC com o título ‘Período de ótimos conhecimentos digitais', no qual expressa que a partir do período da Pandemia da COVID-19 os profissionais utilizarão com mais frequência as Mídias Sociais, pois esses profissionais nesse momento somente obtinham as mídias como opção e a partir disso acabaram se beneficiando, tornando-se mais seguros ao seu uso. Nesse depoimento, esse sujeito coletivo relata também que os conhecimentos digitais adquiridos nesse período facilitarão seu dia a dia no trabalho e considera que as Tecnologias Digitais estão ainda mais em crescimento. 


\section{Edição Especial COVID-19}

Quadro 5 - DSC 5 - Período de ótimos conhecimentos digitais.

Como você percebe o período após a Pandemia de Covid-19 em suas relações de trabalho com as Tecnologias Digitais?

Vejo ainda mais crescimento, porque agora todos sabem o verdadeiro potencial das redes sociais para esses fins, pois estão se beneficiando diretamente mesmo sem querer, certamente maior utilização. Acredito que muitos profissionais que ainda não usavam as mídias sociais irão se sentir mais seguros, pois muitas pessoas ainda tinham vergonha de usar as mídias sociais fazendo vídeos por exemplo, até o momento em que as mídias são sua única opção. Sem dúvidas voltarei mais fortalecido, com ótimos conhecimentos digitais, assim facilitando o dia a dia do meu trabalho, por exemplo, videoconferências direto com meus colegas, especialmente os de Porto Alegre.

Fonte: Pesquisa (2020).

Quadro 6 - DSC 6 - As atividades seguirão no modo tradicional.

Como você percebe o período após a Pandemia de Covid-19 em suas relações de trabalho com as Tecnologias Digitais?

Percebo que ainda é muito debatido na área da psicologia, penso que com dificuldade seguirão nos moldes já utilizados, talvez muitas atividades irão se consolidar pelo meio virtual, porém de forma complementar e não substitutiva, com isso terá mais adesão como trabalho fixo ou extra. Trabalho no hospital, então as tecnologias para mim, são mais para ter o conhecimento sobre a doença e atualização, ademais manterei do mesmo modo que era anteriormente. Provavelmente ela deve ser afastada aos poucos, sendo relevantes para informações básicas, não substituindo o atendimento tradicional, se bem que o serviço online poderá se manter, mas ainda vejo muita resistência dos pacientes, pois o público que eu atendo não tem como ser por redes sociais.

Fonte: Pesquisa (2020).

O sexto DSC é demonstrado no Quadro 6, com o título de 'As atividades seguirão no modo tradicional. ', esse depoimento expressa que após o período da Pandemia da COVID-19 as Tecnologias Digitais serão afastadas, talvez sejam utilizadas de forma complementar ou como um trabalho extra. Esse sujeito coletivo relata também que manterá seus atendimentos como anteriormente, pois o atendimento aos seus pacientes não é possibilitado por redes sociais, assim como, eles possuem resistência as Tecnologias Digitais.

\section{DISCUSSÃO}

Diante dos resultados desta pesquisa foi evidenciado a crescente utilização das Tecnologias Digitais e das Mídias Sociais pelos profissionais da área da saúde. De acordo com os seis depoimentos resultantes das questões abertas, há a expressão da 
dúvida em relação ao uso dessas questões por esses profissionais com a finalidade de auxiliar no âmbito da saúde, assim como é expressado em outros discursos o domínio por essas inovações tecnológicas nessa área.

Há dois olhares perante as Mídias Sociais e as Tecnologias Digitais no uso cotidiano de suas atividades docentes e dos atendimentos na área da saúde, o primeiro é o de dúvida em relação a sua efetividade frente a essas atividades e o segundo é um olhar progressista e que alguns desses profissionais tem possibilitado, talvez por meio da própria circunstância da Pandemia da COVID-19 e assim, a reclusão domiciliar, a prática na utilização desses meios tecnológicos para minimizar os efeitos dessa situação.

O uso do aplicativo WhatsApp se destacou nos resultados desta pesquisa em relação aos demais itens expostos na questão da Figura 5, sob o mesmo ponto de vista esse aplicativo foi utilizado em uma pesquisa no curso de Medicina da Universidade Federal de Uberlândia (UFU) no intuito de discutir o processo de educação em saúde por meio das Mídias Sociais na disciplina de Saúde Coletiva III. Nesse estudo, os autores relataram que houve consenso na proposta do uso do WhatsApp para essa finalidade e que todos os envolvidos tinham acesso a um smartphone e ao aplicativo. (PAULINO et al., 2018).

Segundo o estudo, a estratégia possibilitou a aproximação dos conteúdos teóricos de livros e artigos científicos para a prática profissional médica, de modo acolhedor a realidade da população, permitindo construir saberes éticos, críticos e cooperativos nesse âmbito. Os autores da pesquisa relataram que os resultados obtidos foram positivos devido a organização prévia entre docentes e alunos para a utilização dessa Mídia Social, como a responsabilidade no cumprimento das tarefas, cooperação no decorrer dessas entre os grupos de alunos, da mesma maneira que o desempenho da etiqueta nas Mídias Sociais para esse fim educacional, como por exemplo, dialogar com um grande grupo aguardando o momento de fala do colega. (PAULINO et al., 2018).

Outras Mídias Sociais e Tecnologias Digitais como o Podcast, o Facebook e o Instagram, em que não obtiveram um número expressivo nos resultados desta pesquisa, tem se destacado na literatura. (GOMES et al., 2019; ARAGUÃO et al., 2018; BERNARDES et al., 2019; SOARES et al., 2019). A produção científica tem progredido sobre o uso da Mídias Sociais por profissionais da área da saúde, principalmente no objetivo de elucidar questões em educação em saúde.

Um exemplo na área da enfermagem foi um estudo que delineou a utilização da Mídia Social Facebook na abordagem sobre os temas de saúde sexual e reprodutiva, para o público adolescente escolar. A intervenção educativa com esses jovens foi realizada em grupos secretos na Mídia Social, pois se tratava de um público e um tema em que exige cuidados em sua abordagem. (ARAGUÃO et al., 2018).

Segundo o estudo, a facilidade de interação e o domínio desses adolescentes na Mídia Social Facebook resultou no compartilhamento de conhecimentos sobre os temas, foi ressaltado também pelo estudo que os alunos mais tímidos conseguiram interagir com 
a enfermeira e enfatizaram mais segurança tanto pelo grupo na Mídia Social ser secreto quanto em conversas esclarecedoras em particular com a enfermeira na rede. Os autores ressalvaram a aproximação da escola com o serviço de atenção primária em saúde, bem como a aproximação dos adolescentes com a atenção em saúde e o fortalecimento do vínculo com os profissionais de saúde, revelando a pertinência da necessidade de os profissionais da área reconhecerem os ambientes virtuais como fonte de aproximação com os indivíduos auxiliando no cuidado em saúde e seus contextos sociais. (ARAGUÃo et al., 2018).

Outro estudo utilizando o Facebook, mas na área da Medicina com o intuito de promoção da saúde, os alunos supervisionados pelos docentes desenvolveram uma página nessa Mídia Social com informações baseadas em evidências científicas com linguagem acessível para a comunidade. Além das postagens elucidando alguns temas sobre saúde, os estudantes também respondiam aos comentários e dúvidas surgidas nas postagens. (BERNARDES et al., 2019).

Bernardes et al. (2019), em seu estudo ressaltaram que os estudantes, futuros médicos, puderam vivenciar as experiências de comunicação em tempos de cultura digital, de modo a agir com ética, competência, solidariedade e respeito mútuo. A percepção da abrangência do compartilhamento de informações nas Mídias Sociais e assim, a cautela na responsabilidade de divulgar as informações de modo eficaz, acessível e verídico. (BERNARDES et al., 2019).

Em outro estudo, destinados aos alunos de graduação em Medicina, Ciências Biológicas, Enfermagem e Odontologia, propiciou a esse público alvo um projeto denominado Podcast Café com Saúde. Como o próprio nome do projeto refere, a pesquisa utilizou o Podcast e as áudio-aulas foram organizadas com temáticas interdisciplinares, baseadas em evidências científicas e abordando assuntos atuais, além disso foram publicadas em plataformas virtuais de distribuição como o Spotify e o Castbox. (GOMES et al., 2019).

As áudio-aulas estavam disponíveis gratuitamente nas plataformas mencionadas e obtiveram 10 episódios com os temas: "Saudações; Saúde da Mulher; Embriologia; Esquistossomose; HPV, o que não contaram pra você; Estresse e Ansiedade; A raiva; Câncer de Pele; O vírus HIV; Lúpus Eritematoso Sistêmico." (GOMES et al., 2019, p.158). Os autores ressaltaram a mobilização de docentes e discentes na execução dos episódios dos Podcasts em que gerou a aproximação do conhecimento acessível, a criatividade, assim como a flexibilidade espacial e de gestão individual proporcionada por esse meio no cenário educativo foi constituída como uma ação inovadora. (GOMES et al., 2019).

O atendimento remoto nesse período da Pandemia da COVID-19, como os instrumentos estratégicos da Telessaúde, por exemplo, a Telemedicina, Telefonoaudiologia, Teleodontologia dentre outros, proporcionam uma continuidade na assistência em saúde. Estudos na literatura com essas abordagens tem produzido experiências e evidências científicas em que possibilitam uma discussão benéfica para a implementação adequada dessas estratégicas, não somente para os períodos de 
emergência de saúde pública. (SANTOS; FRANÇA; SANTOS, 2020; CAETANO et al., 2020; DIMER et al., 2020; CARRER et al., 2020; FRANÇA; RABELLO; MAGNAGO, 2019).

Em um estudo de uma unidade docente-assistencial da Escola Bahiana de Medicina e Saúde Pública, em Salvador, Bahia, em que possui um Ambulatório da Comunidade (AC) e realiza a essa comunidade local a assistência em saúde, foi instituído o Teleatendimento. Segundo os autores, foram analisados os prontuários eletrônicos dos pacientes atendidos na $A C$ e selecionados os pacientes com 60 anos ou mais e que possuíam alguma doença crônica, indivíduos esses que possuem maior risco de adoecimento pela COVID-19, posteriormente foram selecionados os indivíduos com doença crônica de outras faixas etárias. (SANTOS; FRANÇA; SANTOS, 2020).

Os Teleatendimentos foram realizados por chamada de vídeo via celular, para aqueles pacientes que não concordaram com essa estratégia foi agendado um atendimento presencial na unidade com todas os cuidados necessários, mas ainda segundo o estudo dos 17 Teleatendimentos somente 3 pacientes necessitaram se deslocar para a unidade. As limitações e desafios descritos pelo estudo são a necessidade de exame físico, impossibilidade de acesso as Tecnologias Digitais, nenhuma ou pouca privacidade no momento da Teleconsulta por moradores da residência do paciente e a necessidade de prescrição medicamentosa, por exemplo. (SANTOS; FRANÇA; SANTOS, 2020).

As oportunidades descritas nesse estudo são a de que o Teleatendimento apresenta a possibilidade de não expor esses pacientes ao vírus da COVID-19 no deslocamento até a unidade e esse deslocamento também impacta, por exemplo por vezes em limitações físicas e econômicas. Assim como, na contribuição da diminuição do abandono permitindo a manutenção do vínculo dos indivíduos da comunidade local com o serviço em saúde. (SANTOS; FRANÇA; SANTOS, 2020).

Vai de encontro com o depoimento DSC 4 do Quadro 4 desta pesquisa, em que o sujeito expõe a importância das Tecnologias Digitais para manter o contato com os pacientes nesse período da pandemia. O acolhimento e o cuidado em saúde auxiliam no enfrentamento desse período da Pandemia da COVID-19, como também essa flexibilidade no atendimento virtual seja, por exemplo, na realização de consulta, orientação e/ou monitoramento, possibilita a diminuição da sobrecarga nas redes de urgências e emergências locais. (CAETANO et al., 2020).

Talvez, nem todas as possibilidades do uso das Mídias Sociais e das Tecnologias Digitais sejam igualmente eficazes para determinadas situações na assistência em saúde e/ou para determinadas áreas dessa, como por exemplo, no depoimento do DSC 6 no Quadro 6 em que foi evidenciado o afastamento das Mídias Sociais e das Tecnologias Digitais do cotidiano nos atendimentos entre profissionais e pacientes e/ou nas atividades acadêmicas desses, após a pandemia. Provavelmente em alguns casos sejam essas as ações que prevalecerão após a pandemia, no entanto no DSC 5 no Quadro 5, aquele sujeito coletivo expressa um olhar otimista no uso dessas inovações tecnológicas no âmbito do cotidiano dos profissionais de saúde, assim como 


\section{Edição Especial COVID-19}

ressalva que esse período proporcionou um fortalecimento em relação aos conhecimentos digitais.

\section{CONSIDERAÇÕES FINAIS}

Na pesquisa realizada foi evidenciado que há dois olhares perante o uso das Mídias Sociais e das Tecnologias Digitais pelos profissionais da área da saúde em seu cotidiano de atividades docentes e de atendimentos na assistência em saúde, o primeiro é o de dúvida em relação a sua efetividade frente a essas atividades, visto que o atendimento presencial nessa área é essencial. E como foi mencionado em alguns depoimentos desta, assistências em saúde como o tratamento fisioterapêutico ou em algum atendimento hospitalar não possibilita a atividade por meio dessas ferramentas.

E o segundo é um olhar progressista e que alguns desses profissionais tem possibilitado, talvez por meio da própria circunstância da Pandemia da COVID-19 e assim, a reclusão domiciliar, a prática na utilização desses meios tecnológicos para minimizar os efeitos dessa situação. Com isso, a comunicação virtual possibilitou a manutenção do contato com pacientes e/ou alunos, minimizando o efeito de abandono, nesse período.

E é nesse sentido que esta pesquisa se propõe, da possibilidade de reflexão no desenvolvimento de competências e habilidades virtuais e também em fomentar a relação dos profissionais dessa área com as Tecnologias Digitais e as Mídias Sociais. Certamente, com uma análise prévia dos casos e contextos sociais dos pacientes e alunos por esses profissionais que assim optarem, seja na utilização das Mídias Sociais e das Tecnologias Digitais em complementar ou substituir suas interações com esses.

Nesse sentido, acredita-se que os profissionais da saúde em formação sejam esses atuantes em suas especialidades e/ou docência na área, necessitam desprender-se do modo obsoleto das aulas expositivas e totalmente presenciais e compreender as demandas atuais. Do mesmo modo, que refletir na inserção dessas ferramentas como condutas de aproximação com seus pacientes e/ou alunos.

\section{REFERÊNCIAS}

ARAGUÃO, J. M. N. et al. O uso do facebook na aprendizagem em Saúde: percepções de adolescentes escolares. Revista Brasileira de Enfermagem, v.71, n.2, p.286292, 2018.

AVELINO, W. F.; MENDES, J. G. A realidade da Educação brasileira a partir da COVID-19. Boletim de Conjuntura (BOCA), v.2, n.5, p.56-62, 2020.

BARRETO, M. L. et al. O que é urgente e necessário para subsidiar as políticas de enfrentamento da pandemia de COVID-19 no Brasil?. Revista Brasileira de

Epidemiologia, v.23, e200032, p.1-4, 2020. 
BERNARDES, V. P. et al. Facebook ${ }^{\circledR}$ como ferramenta pedagógica em Saúde Coletiva: integrando formação médica e educação em Saúde. Revista Brasileira de Educação Médica, v.43, n.1, Supl.1, p.652-661, 2019.

BRASIL. COVID-19. Brasília: Ministério da Saúde, 2020. Disponível em: https:// coronavirus.saude.gov.br/sobre-a-doenca\#o-que-e-covid. Acesso em: 17 mai. 2020.

BRASILEIRO, A. M. M. Manual de produção de textos acadêmicos e científicos. São Paulo: Atlas, 2013.

CAETANO, R. et al. Desafios e oportunidades para telessaúde em tempos da pandemia pela COVID-19: uma reflexão sobre os espaços e iniciativas no contexto brasileiro.

Cadernos de Saúde Pública, v.36, n.5, e00088920, 2020.

CARRER, F. C. A. et al. Teleodontologia e SUS: uma importante ferramenta para a retomada da atenção primária à saúde no contexto da pandemia de COVID-19.

SciELO Preprints, 2020. DOI: https://doi.org/10.1590/SciELOPreprints.837. Disponível em: https://preprints.scielo.org/index.php/scielo/preprint/view/837/1159. Acesso em: 25 jun. 2020.

CECCON, R. F.; SCHNEIDER, I. J. C. Tecnologias leves e educação em saúde no enfrentamento à pandemia da COVID-19. SciELO Preprints, 2020. Disponível em: https://preprints.scielo.org/index.php/scielo/preprint/view/136/version/141. Acesso em: 19 mai. 2020.

CHURKIN, O. M. Educação à distância um marco civilizatório, um olhar holístico da pedagogia: sinergia e reflexões na conectividade em tempos de COVID-19. Brazilian Journal of Health Review, v.3, n.2, p.3178-3196, 2020.

DIMER, N. A. et al. Pandemia do COVID-19 e implementação de telefonoaudiologia para pacientes em domicílio: relato de experiência. CoDAS, v.32, n.3, e20200144, 2020.

FRANÇA, T.; RABELLO, E. T.; MAGNAGO, C. As mídias e as plataformas digitais no campo da educação permanente em saúde: debates e propostas. Saúde em Debate, v.43, n.especial 1, p.106-115, 2019.

GUIMARÃES, F. Atuação do fisioterapeuta em unidades de terapia intensiva no contexto da pandemia de COVID-19. Fisioterapia em Movimento, v.33, e0033001, p.1-3, 2020.

GOMES, R. M. C. M. et al. Café com saúde: podcast como ferramenta de ensino nos cursos de saúde. In: CONGRESSO SOBRE TECNOLOGIAS NA EDUCAÇÃO, 4., 2019, Recife. Anais... Recife: UFPE, 2019. p.155-163.

LEFÈVRE, F.; LEFÈVRE, A. M. C. Discurso do sujeito coletivo: um novo enfoque em pesquisa qualitativa (desdobramentos). 2. ed. Caxias do Sul: Educs, 2005.

LEFÈVRE, F.; LEFÈVRE, A. M. C. Discurso do sujeito coletivo: representações sociais e intervenções comunicativas. Texto e Contexto Enfermagem, v.23, n.2, p.502-507, 2014. 
LEFÈVRE, F. et al. O discurso do sujeito coletivo como eu ampliado: aplicando a proposta em pesquisa sobre a pílula do dia seguinte. Revista Brasileira de Crescimento e Desenvolvimento Humano, v.20, n.3, p.798-808, 2010.

MENDONÇA, C. S. et al. Resposta assistencial de um serviço docente assistencial de aps à pandemia do COVID-19. APS em Revista, v.2, n.1, p.33-37, 2020.

MOOCK, M.; MELLO, P. M. V. C. Pandemia COVID-19. Revista Brasileira de Terapia Intensiva, v.32, n.1, p.1, 2020.

OMS. Preguntas y Respuestas sobre la Enfermedad por Coronavirus (COVID19). Organização Mundial da Saúde, 2020a. Disponível em: https://www.who.int/es/ emergencies/diseases/novel-coronavirus-2019/advice-for-public/q-a-coronaviruses. Acesso em: 17 mai. 2020.

OMS. Coronavírus. Organização Mundial da Saúde, 2020b. Disponível em: https:// www.who.int/es/health-topics/coronavirus/coronavirus. Acesso em: 17 mai. 2020.

OPAS. Folha Informativa COVID-19. Organização Pan-Americana da Saúde, 2020. Disponível em: https://www.paho.org/bra/index.php?option=com_content\&view= article\&id=6101: covid19\&ltemid=875. Acesso em: 17 mai. 2020.

PALÁCIO, M. A. V.; TAKENAMI, L. Em tempos de pandemia pela COVID-19: o desafio para a educação em saúde. Revista Visa em Debate, v.8, n.2, p.10-15, 2020.

PAULINO, D. B. et al. Whatsapp ${ }^{\circledR}$ como recurso para a educação em saúde: contextualizando teoria e prática em um novo cenário de ensino-aprendizagem. Revista Brasileira de Educação Médica, v.42, n.1, p.169-178, 2018.

SANTOS, A. B. S.; FRANÇA, M. V. S.; SANTOS, J. L. F. Atendimento remoto na APS no contexto da COVID-19: a experiência do ambulatório da comunidade da escola bahiana de medicina e saúde pública em Salvador, Bahia. APS em Revista, v.2, n.2, p.169-176, 2020.

SOARES, L. C. C. et al. Utilização das mídias sociais para educação em saúde pela LAPFITO: do Instagram a oficinas de saúde e a interação entre academia e comunidade. In: SEMINÁRIO DE TECNOLOGIAS APLICADAS EM EDUCAÇÃO E SAÚDE, 4., p.207-214, 2019. Anais... Salvador: UNEB, 2019. 